\title{
Playful maths! The influence of play-based learning on academic performance of Palestinian primary school children
}

\author{
Elaine M. Murtagh ${ }^{1,2}$ (D) Jamil Sawalma ${ }^{3} \cdot$ Rosemarie Martin $^{4}$ \\ Received: 4 December 2020 / Accepted: 17 January 2022 / Published online: 11 February 2022 \\ (c) The Author(s) 2022
}

\begin{abstract}
This study explores the relationship between play-based learning and achievement in mathematics in Palestinian elementary school children. Forty teachers from eight schools received training in play-based pedagogies and follow-up support visits from programme staff (intervention group); four matched schools served as the control group. Grade-appropriate tests were administered to all students in two consecutive school terms. A total of 859 students (458 females, 401 males) and 832 students (477 females, 355 males) completed maths tests in term 1 and 2, respectively. Results revealed that the intervention group attained higher test scores than the control group in both terms $(P<0.01)$. Furthermore, in term 2 an interaction effect between group and gender was found $(P<0.05)$, with girls in the intervention group achieving the highest scores. Our finding suggest that play-based learning approaches may enhance academic achievement.
\end{abstract}

Keywords Learning $\cdot$ Teaching $\cdot$ Play $\cdot$ Palestine $\cdot$ Mathematics $\cdot$ Academic success

\section{Introduction}

The last decade has witnessed a general shift in educational pedagogy aimed at enhancing the educational experiences of young children (Bennett \& Tayler, 2006). Government policies internationally are promoting child-centred pedagogies (e.g. Government of Ireland, 1999). Enacting a child-centred approach allows children to become active participants in their learning processes rather than passive recipients of knowledge (Dewey, 1906). Education is centred on their needs and abilities and the teacher takes on the role of facilitator in the learning process rather than the provider of knowledge (de la Sablonnière et al., 2009). Through

Elaine M. Murtagh

elaine.murtagh@ul.ie

1 Department of Physical Education and Sport Sciences, University of Limerick, Limerick, Ireland

2 Physical Activity for Health Research Cluster, Health Research Institute, University of Limerick, Limerick, Ireland

3 Right To Play, Wadia'a Shatara Street, Al-Fatina Bdg.14, Ramallah, Palestine

4 Faculty of Education, Mary Immaculate College, South Circular Road, Limerick, Ireland 
engaging in active learning approaches such as hands-on learning where pupils learn by doing (Dewey, 1906), student-centred instruction where pupils are viewed as active agents in their own learning (Government of Ireland, 1999), play-based learning where learners are facilitated to explore and engage with their environment and interact socially with others (Cornelli Sanderson, 2010; Zosh et al., 2018), and co-operative learning which involves the combined efforts of learners working together (Johnson et al., 1998), children participate in 'real world' tasks which promote the development of deep levels of understanding (Biggs, 2011). This far exceeds surface knowledge, rote learning and memorising skills required to perform well in traditional assessments (de la Sablonnière et al., 2009). Active educational approaches have been found to promote greater class participation among students; contribute towards building a society of effective and efficient problem solvers through engaging children in higher order thinking; and support the development of students' performance skills by building on their strengths and needs throughout the process (Darling, 1994; Darling-Hammond, 1994).

Play is widely recognised as a means of engaging children actively in their learning, particularly in early years education; however, the effectiveness of play as a pedagogical approach has been disputed in the research literature. Overall, there is consensus on the effectiveness of play to promote children's development in areas such as socialisation, enjoyment, problem solving, physical and emotional development as well as their overall wellbeing (Ghafouri \& Wien, 2005; Hunter \& Walsh, 2014). However, many debate the effectiveness of play for academic learning (Zosh et al., 2018). Zosh et al. (2018) argue that much of this disagreement can be attributed to the difficulty in defining play. Through reviewing the literature on play and learning Zosh et al. (2018) conceptualise play as a spectrum ranging from free play to guided play, games, and playful instruction. Movement through the spectrum is dependent on who initiates the play (child/ adult), who directs the play (child/ adult) and whether there is an explicit learning goal. During free play the child instigates and leads the play without guidance, input, or support from an adult and there is no extrinsic goal (Zosh et al., 2018). Guided play, while being led by the child is initiated by the adult who creates the context, scaffolds the activity, and provides effective feedback focussed on a learning outcome (Alfieri et al., 2011; Zosh et al., 2018). Playful instruction is a more structured form of playful learning as it aims to achieve an explicit learning outcome while being both initiated and directed by the adult (Zosh et al., 2018).

In recent years, the effect of various types of play on children's academic performance has been examined (Kotsopoulos et al., 2015). In their meta-analysis of 164 studies, Alfieri et al. (2011) compared the effectiveness of unassisted discovery learning, assisted discovery learning and explicit instruction. They found that assisted discovery approaches led to better learning outcomes than unassisted discovery learning or explicit instruction (Alfieri et al., 2011). In their review of 74 studies examining play for academic achievement, Pyle et al. (2017) also report that guided play (both teacher-directed and mutually directed play) has been found to best support children's general academic learning, and contributes to their oral language, reading, writing, scientific and mathematical skills. Much of the existing literature focuses on play in pre-school settings with little reference to play beyond the early years in primary education (Hunter \& Walsh, 2014). Primary school aged children are; however, included in the studies by Bustamante et al. (2020) and Habgood and Ainsworth (2011) in which the authors evaluate the effectiveness of two distinct types of playful learning on academic outcomes. Bustamante et al. (2020) evaluated the effectiveness of a life-sized science and maths board game (Parkopolis) located in a children's museum on children's STEM skills. 749 children aged between 3 and 7 years engaged with Parkopolis. Although the authors note that most of the children were preschool age (3-5 years), they conclude that such playful learning experiences can augment developmentally appropriate STEM concepts 
children learn in early childhood and primary school (Bustamante et al., 2020). Habgood and Ainsworth (2011) developed a digital game to teach Maths to 7-11-year-olds. In this study, the authors highlight the effectiveness of intrinsic integration i.e. delivering academic content through the fun elements of the game (see Habgood and Ainsworth (2011) for a more detailed definition). Both Bustamante et al. (2020) and Habgood and Ainsworth (2011) emphasise the importance of guided interactions with the teacher or caregiver during the learning process to bring about learning in STEM/ mathematics.

Science of learning illustrates that children learn best when they are actively (mindson) engaged in meaningful (linked to prior knowledge and transferrable to the real world) learning which occurs in socially interactive environments (Hirsh-Pasek et al., 2015). Zosh et al. (2018) contend that guided play achieves best academic outcomes because it harnesses the features of an optimal learning environment as well as joy (positive affect) and iteration (construction of new knowledge through hypothesis testing (Piaget, 1962)) "more so than any other types of play" (Zosh et al., 2018, p 4). Joy, intrinsic motivation and iteration are inherent characteristics of play (Krasnor \& Pepler, 1980; Piaget, 1962) and have been found to result in advanced executive functioning and academic achievement (Diamond, 2014). Lazonder and Harmsen (2016) found in their meta-analysis that iteration is enhanced through guided play because adult support brings about more advanced hypothesis testing and experimental design resulting in more advanced learning for the child. Therefore, to optimise learning, children must engage in playful learning in which they are facilitated with fun child-centred opportunities to explore and discover while being scaffolded, guided, supported and provided with effective feedback towards a learning outcome (Alfieri et al., 2011; Hirsh-Pasek et al., 2009).

Since playful learning has been found to be more engaging and developmentally appropriate for children than didactic teaching strategies (Alfieri et al., 2011; Balfanz et al., 2003; Sarama \& Clements, 2006) it is beginning to receive a central position in policy and curriculum development internationally. Play underpins curriculum development in countries such as Australia (Sumsion et al., 2009), Canada (Lynch, 2015), China (Pan \& Li, 2012), Greece (Tafa, 2008), India (Hegde \& Cassidy, 2009), Ireland (Gray \& Ryan, 2016), Japan (Hegde \& Cassidy, 2009), New Zealand (Synodi, 2010), Norway (Synodi, 2010), Singapore (Ling-Yin, 2006), South Korea (Kim, 2004), Sweden (Synodi, 2010), United Arab Emirates (Baker, 2014a) and the United Kingdom (Tafa, 2008).

However, although playful learning pedagogies have been well endorsed in government policies in many parts of the globe, much of the literature discusses the many perceived barriers to implementing play as pedagogy in primary education (Hunter \& Walsh, 2014). Lack of provision, insufficient resources, space constraints, confusion around the role of the teacher, parental expectations, emphasis on academic achievement, and cultural practices and beliefs are some of the constraints affecting the quality, frequency and duration of play as pedagogy (Fung \& Cheng, 2012; McInnes et al., 2011; Moyles, 2014; Pyle et al., 2017). Key stakeholders in early childhood education settings in Hong Kong, and India expressed that large class sizes and space constraints restrict children from moving around, resulting in pupils sitting quietly, working on written assignments rather than engaging in play-based learning (Fung \& Cheng, 2012; Hegde \& Cassidy, 2009) Additionally, teachers explained that schools lack appropriate play materials such as blocks, board games, and writing materials (Hegde \& Cassidy, 2009).Pyle et al. (2017) report that similar concerns have been expressed by stakeholders in a range of diverse countries (e.g. China, Canada, Ireland, U.A.E.). Global evidence is demonstrating that primary school teachers are experiencing tensions between competing demands of play-based approaches and curricular demands (Brooker \& Edwards, 2010; Wood, 2014). Existing research is also highlighting that teachers lack understanding 
of how children learn through play (Gray \& Ryan, 2016). It has been widely reported that many teachers view the concepts of play and learning as distinct constructs (Baker, 2014a; Lynch, 2015; Pramling Samuelsson \& Johansson, 2006; Vong, 2012). Fung and Cheng (2012) and Baker (2014a) have reported that teachers find it difficult to identify how play activities can lead to learning. Fung and Cheng (2012) also report parental preferences for didactic instruction over play which is echoed in studies conducted in Canada (Lynch, 2015), India (Hegde \& Cassidy, 2009), South Korea (Kim, 2004), and the United Arab Emirates (Baker, 2014b). In their recent review of play-based learning, Pyle et al. (2017) highlight that this distinct view of play and learning may inhibit teachers' abilities to implement play-based pedagogy in the classroom.

In addition to competing policy demands, and a lack of familiarity and understanding of play-based pedagogical approaches in primary education, a deficiency in training provision has also been identified as impeding the effective use of play-based approaches to learning (Hyvonen, 2011; Moyles, 2014; Pui-Wah \& Stimpson, 2004). Teachers acknowledge that throughout their educational programmes, they have been educated on a spectrum of pedagogical styles including play however, it emerges quite strongly in the literature that teachers feel they need additional training and professional development on how to use play as a vehicle for learning in the classroom (Fung \& Cheng, 2012; Pyle et al., 2017). In many studies, teachers recognise the value of play but lack professional support and resources to use it in practice (Fung \& Cheng, 2012; Pui-Wah \& Stimpson, 2004; Pyle et al., 2017). This combined with the barriers mentioned above highlight the lack of implementation of play as a pedagogy to teach academic content in primary classrooms internationally.

Given the emphasis government policies are placing on the role of play in primary education, teachers are obliged to change their perceptions towards teaching academic content through play (Wallerstedt \& Pramling, 2012). However, this can only be achieved through the provision of appropriate training on play-based approaches which fosters an understanding of the benefits of play, validates the relationship between play and learning and illustrates the supportive role of the teacher in the process (Alfieri et al., 2011; Pramling Samuelsson \& Carlsson, 2008).

\subsection{Education in Palestine}

A long history of social and political conflict and upheaval in Palestine resulted in a lack of educational resources and facilities so that academic achievement levels and school attendance rates were among the lowest in the world (UNESCO, 1991). The education system failed to meet the needs of students and pressed them to leave school and enter the work force at a young age (Al-Ramahi \& Davies, 2002; Khales \& Meier, 2013). The ratification of the United Nations Convention on the Right of the Child (UNCRC), by the State of Palestine in 2014 placed children's rights at the centre of social and political agendas. All children now have a right to free primary education and restrictions are placed on the employment of children (UNESCO, 1991). In recent years, pedagogic practice in Palestinian primary schools has undergone great reform to improve the quality of their education system towards meeting economic and social needs (Shinn, 2012). However, teaching methods in Palestine remain very much teacher centred, with didactic pedagogies and lecture type teaching where students passively acquire knowledge (Al-Ramahi \& Davies, 2002; Khales \& Meier, 2013). Textbooks classified according to student age contain the official material to be taught in schools and emphasis is largely on meeting official requirements of a subject-based curriculum rather than the learning process (Khales \& Meier, 2013). Maths is one of the core 
curricular subjects in which this textbook based, didactic type teaching is prominent in Palestinian primary schools (Al-Ramahi \& Davies, 2002). To meet social and economic needs, as well as the needs of the children a change from this passive learning approach towards a child-centred playful learning approach is recommended (Shinn, 2012). This necessitates a change in both students' and teachers' attitudes and behaviours. Therefore, it is important that extensive professional development training and support are provided to teachers to deepen their knowledge and instructional expertise (Khales \& Meier, 2013).

Despite the many identified benefits of playful learning for both academic and developmental learning, there is a dearth of research on the effects of this pedagogy on primary school academic outcomes (McGuinness et al., 2014). As it is essential to validate the relationship of play and learning - particularly in the primary school setting, if primary school educational professionals and key stakeholders are to buy-in to using this pedagogy (Pramling Samuelsson $\&$ Carlsson, 2008), this study aims to examine the relationship between play-based learning and students' mathematic achievement in Grades 1-4 in Palestinian primary schools. Since mathematics has been identified as one of the core curricular areas in which students engage in passive learning in Palestinian classrooms (Al-Ramahi \& Davies, 2002), this study will focus on teaching mathematics concepts through play. Finally, reflecting the research highted above, in the current study playful learning can be defined as 'an experiential, participatory and guided approach, which enhances the teaching and learning process. Through play-based learning children ....actively engage with their peers and leaders in educational games and activities' (Right To Play, 2017). This paper addressed the following research question: Do primary schoolchildren who are taught mathematics using play-based learning pedagogies attain higher scores in maths tests compared to those taught using traditional practices?

\section{Methods}

\subsection{Study design}

This non-randomised parallel group study was conducted in the 2018/19 school year. The population of interest is children attending primary schools in Palestine. This paper analyses data collected as part of a project examining the impact of play-based learning in Palestinian schools (Turshan, 2019). The purpose of the original study was to examine the extent of the relationship between play-based learning methodologies and acquiring numeracy skills / mathematic subject knowledge of students. Data were originally collected for internal monitoring and evaluation process and to provide reports to funders.

\subsection{Setting}

The Transforming Attitudes, Approaches and Learning Outcomes Across the Middle East (TAALOM) project was implemented by the NGO Right To Play (Right To Play, 2020). Primary schools were recruited from the Qabatiya district of Palestine. Schools were located in rural areas, considered to be of moderate socioeconomic status. In this paper, we use data collected during term 1 (September-December 2018) and term 2 (February-April 2019) of the school year 
Table 1 Characteristics of included schools

\begin{tabular}{llll}
\hline School & Gender & Total students in school & Grades in this study \\
\hline Intervention group & & & \\
School A & F & 237 & $2,3,4$ \\
School B & Mixed & 259 & 3,4 \\
School C & F & 337 & 3,4 \\
School D & Mixed & 281 & 3,4 \\
School E & M & 388 & 1,2 \\
School F & F & 256 & 1,2 \\
School G & M & 614 & 1,2 \\
School H & F & 371 & 1 \\
Control Group & & & $1,2,3,4$ \\
School I & M & 431 & $1,2,3,4$ \\
School J & F & 325 & $1,2,3,4$ \\
School K & F & 388 & $1,2,3,4$ \\
School L & F & 367 &
\end{tabular}

\subsection{Participants}

Students in grade $1-4$, and their teachers, from 12 primary schools participated in the study. A letter was sent from the Ministry of Education to the school principals, to invite their school to take part in the project. This was followed up with contact from [masked for review] to explain the detail of the project. Grades 1-4 were used in the present study as they are collectively considered the "preparatory stage" of compulsory basic education in Palestine. Eight schools were selected as the intervention group (16 classes in total, four at each grade level) and four schools matched by contextual reference, e.g. teacher qualification, student's academic success, served as the control group (16 classes, 4 at each grade level). There were a similar total number of students in both groups; with 415 students in the intervention group and 444 in the control group completing the term 1 exam. These schools were selected by the Ministry of Education and [masked for review] as they were located in a marginalised areas and had not received any training from [masked for review] previously. Control schools were required not to have previously received training in play-based learning methods. The control group continued with usual practice for the duration of the programme. Table 1 provides an overview of the characteristics of the included schools. $85 \%$ of teachers were female, aged 25-45 years with 5-15 years' teaching experience.

\subsection{Variables and data sources}

The primary outcome was test scores in mathematics assessed during a school-based test at the end of each semester (i.e. December 2018 and May 2019). Tools were purposively developed to assess attainment of learning outcomes of the Palestinian mathematics curriculum for each grade level. The tool was developed by a panel of education supervisors, ${ }^{1}$

1 Educational supervisors, called "inspectors" in some countries, are employed by the Ministry of Education to conduct school visits where teachers are observed, mentored and supported. A report is then provided to the Ministry of Education. 
including a supervisor with expertise in mathematics education ( $n=5,60 \%$ female). An external consultant facilitated a series of workshops where the panel reviewed the mathematics curriculum for grade 1-4 and subsequently developed school-based tests for each level. Feedback was sought from the Ministry of Education and Higher Education and revisions were made. Appendix 1 summarises the curriculum outcomes that were assessed for each grade level. A sample of one of the maths tests are also provided in Appendix 2. The tests included 15-20 questions that assessed the children on the learning outcomes covered during the semester. The tests were specific to each grade level. Types of questions included identifying missing numbers on a number-line, ordering numbers, rounding numbers, completing operational sums (addition, subtraction, multiplication, division), counting in multiples of a numbers, identifying and naming shapes and angles, colouring a fraction of a set, identifying the fraction of a shape that is coloured, stating the place value of digits, creating graphs and solving data questions, and problem solving. Educational supervisors administered the test during normal school hours. The supervisors were not masked to group assignment.

\subsection{Play-based learning programme}

Right To Play works in 15 countries worldwide to protect, educate and empower children to rise above adversity using the power of play (Right To Play, 2020). Teachers attending the intervention schools received training in the use of play-based learning methods from Right To Play staff (intervention group). The type of play utilised in the programme is considered "guided play and games" in that the teacher is involved in initiating the activities which are focussed on learning outcomes. Teachers used a "Reflect-Connect-Apply" strategy to assess their students learning and guide them accordingly on their learning journey. This strategy involved discussions within the guided play activities in which teachers facilitated the children to reflect on their experiences, connect those experiences to their prior knowledge and apply their new learning to their daily lives and in their future learning. The play-based learning programme is underpinned by the creation of a positive child-centred learning environment.

Teachers received 16 days of training over three years. The training aimed to provide teachers with the knowledge, skills and attitudes necessary to teach the national numeracy curriculum objectives using child-centred, play-based approaches. About 40 teachers from the eight intervention schools attended the compulsory training. These training events were delivered as experiential learning workshops and covered topics such as: child-centred pedagogy, play-based learning approaches; positive learning environment; Reflect-ConnectApply methodology, inclusion, child protection and gender; positive discipline; life skills (see Table 2 for an overview of the workshop topics). Teachers also received a manual outlining some general ideas to support numeracy teaching, the Curriculum Framework developed by Right To Play and examples of games and play-based activities. The activities are linked to the four numeracy strands (Number sense, Measurement, Spatial Sense and Data Management) and are divided into three learning stages (Early Numeracy, Emerging Numeracy and Expanding Numeracy) to reflect a student's learning journey across primary school. Key objectives, prior knowledge, equipment needed, discussion points, activity instructions, as well as ideas for assessment, variation, extension, adaption and inclusion are outlined for each activity. Each activity begins with a discussion to access the students' prior knowledge. The children then engage in guided play which incorporates the reflect-connect-apply approach to teach the mathematical concept (see Appendix 3 for examples of activities provided to teachers). Teachers were encouraged to adapt the games and activities to meet the needs of the children and their own teaching requirements. Equipment was provided to schools, such 
Table 2 An overview of content in the teacher workshops

\begin{tabular}{|c|c|}
\hline Area & Topics \\
\hline $\begin{array}{l}\text { Play-based learning foundations } \\
\text { This introductory area of learning provided the foundation } \\
\text { for further professional development relating to } P B L\end{array}$ & $\begin{array}{l}\text { - Building community } \\
\text { - Child development } \\
\text { - Play-based learning } \\
\text { - Reflect-Connect-Apply } \\
\text { Practical play-based learning experience } \\
\text { - Engaging children } \\
\text { - Core principles of a positive learning } \\
\text { environment }\end{array}$ \\
\hline $\begin{array}{l}\text { Play-based learning in practice } \\
\text { This area of learning supported teachers to examine their } \\
\text { curriculum and apply PBL approaches }\end{array}$ & $\begin{array}{l}\text { - Universal truths of learning } \\
\text { - Knowing your curriculum } \\
\text { - Literacy and numeracy } \\
\text { - Planning and demonstrations } \\
\text { - Reflect-connect-apply (advanced) } \\
\text { - Modifying games for the curriculum } \\
\text { - Working with large groups }\end{array}$ \\
\hline $\begin{array}{l}\text { Creating a positive learning environment for play-based } \\
\text { learning } \\
\text { This area of learning supported teachers to build a safe and } \\
\text { effective environment for all students when enacting PBL }\end{array}$ & $\begin{array}{l}\text { - Child-centred learning } \\
\text { - Inclusion } \\
\text { - Child safety } \\
\text { - Positive behaviour management } \\
\text { - Gender equality } \\
\text { - Family engagement }\end{array}$ \\
\hline
\end{tabular}

as beanbags marked with letters, numbers and mathematical symbols. Teachers also received approximately 640 follow-up visits to their schools to provide mentoring and support. This included lesson observations followed by feedback and discussion with the teacher. Observation sheets were completed. Areas agreed for development were then followed up during the next visit. Data for the current study were collected in year 3 of the programme.

\subsection{Analysis}

Analysis were conducted using SPSS version 26 (SPSS Inc, Chicago, UL). Descriptive statistics were run to present mean and standard deviations for variables of interest. Preliminary examination of the data showed that the data was skewed, which is a typical observation with test score data of this kind. We conducted the analysis for the main effect using a Mann Whitney $U$ test and a significant difference was found. Given that many statisticians support the use of parametric statistics in these conditions (Blanca et al., 2017; le Cessie et al., 2020), and the need to examine interactions and control for covariates, we proceeded with the reporting of parametric tests in this paper. The main outcome measure, i.e. test scores, was examined using a Factorial ANOVA with group and gender as fixed factors, and grade as a covariate.

\section{Results}

A total of 859 students (458 females, 401 males) completed the examination in semester 1, while 832 students completed the exam in semester 2 (477 females, 355 males). Further detail of the subject numbers by grade and group can be seen in Table 3 . There was attrition 
Table 3 Participant characteristics

\begin{tabular}{|c|c|c|c|c|c|c|c|c|c|}
\hline & & \multicolumn{4}{|c|}{ Intervention } & \multicolumn{4}{|c|}{ Control } \\
\hline & & \multicolumn{2}{|c|}{ Term 1 exam } & \multicolumn{2}{|c|}{ Term 2 exam } & \multicolumn{2}{|c|}{ Term 1 exam } & \multicolumn{2}{|c|}{ Term 2 exam } \\
\hline & & $n$ & $\%$ & $n$ & $\%$ & $n$ & $\%$ & $n$ & $\%$ \\
\hline \multirow[t]{2}{*}{ Gender } & $\mathrm{F}$ & 249 & $60.0 \%$ & 227 & $59.0 \%$ & 209 & $47.1 \%$ & 250 & $55.9 \%$ \\
\hline & M & 166 & $40.0 \%$ & 158 & $41.0 \%$ & 235 & $52.9 \%$ & 197 & $44.1 \%$ \\
\hline \multirow[t]{4}{*}{ Grade (n) } & 1 & 103 & $24.8 \%$ & 111 & $28.8 \%$ & 115 & $25.9 \%$ & 107 & $23.9 \%$ \\
\hline & 2 & 115 & $27.7 \%$ & 107 & $27.8 \%$ & 107 & $24.1 \%$ & 114 & $25.5 \%$ \\
\hline & 3 & 104 & $25.1 \%$ & 84 & $21.8 \%$ & 114 & $25.7 \%$ & 118 & $26.4 \%$ \\
\hline & 4 & 93 & $22.4 \%$ & 83 & $21.6 \%$ & 108 & $24.3 \%$ & 108 & $24.2 \%$ \\
\hline Total number & & 415 & & 385 & & 444 & & 447 & \\
\hline
\end{tabular}

F, female; M, male; n, number of participants

in term 2 as not all children presented for the second assessment in term 2 . We believe these are data missing completely at random (MCAR) and therefore imputation is not requited (Bennett, 2001).

Figure 1 shows test scores by group and gender for each semester. The mean score for the intervention groups in term 1 and term 2 was $85.8(\mathrm{SD}=19.8)$ and $85.9(\mathrm{SD}=17.3)$, respectively. Corresponding scores from the control group in term 1 and 2 were 71.1 (SD $=24.9)$ and $69.2(\mathrm{SD}=25.0)$. There was a significant main effect for group, with the intervention group attaining higher test scores in term $1, F(1,854)=87.1, P<0.001)$, $(85.8$ vs 71.1$)$ and semester $2, F(1,827)=115.6, P<0.001$, (85.9 vs 69.2$)$. The main effect for gender was not significant (Term $1 p=0.25$; Term $2 p=0.91$ ). The mean score for the intervention group in term 1 was $86.1(\mathrm{SD}=19.7)$ for females and $85.3(\mathrm{SD}=20.0)$ for

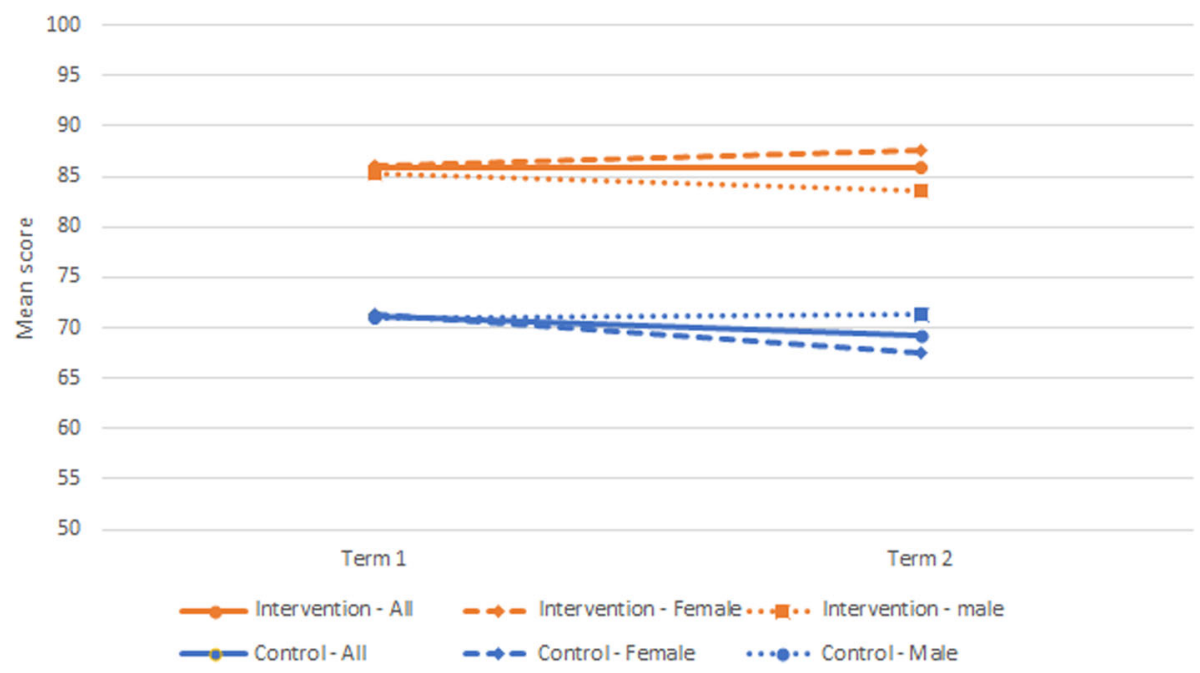

Fig. 1 Mean scores in term 1 and term 2 
males. Corresponding term 1 scores for the control group was $71.3(\mathrm{SD}=24.8)$ for female students and $70.9(\mathrm{SD}=25.1)$ for male students. There was no interaction effect between group and gender for the term 1 examination scores, $F(1,854)=424.3, p=0.348)$. However, in term 2 there was a statistically significant interaction between group and gender on test score, whilst controlling for grade, $F(1,827)=6.75, p=0.01$; intervention females $M=$ 87.6 ( $\mathrm{SD}=14.9)$, intervention males $M=83.5$ ( $\mathrm{SD}=20.1)$, control females $M=67.6$ ( $\mathrm{SD}=25.4)$, control males $M=71.3(\mathrm{SD}=24.5)$. Girls in the intervention group achieved similar scores to the boys in term 1 and attained higher scores in term 2.

\section{Discussion}

The study sought to examine the relationship between play-based learning and students' achievement in mathematics in Palestinian primary schools. The main effect observed for group indicates a significant difference in the test scores attained by the intervention group versus the control group in both term 1 and term 2 assessments. Students in schools where teachers received training in play-based pedagogies attained higher scores. Much of the research thus far has focussed on early childhood setting, this paper therefore augments the body of evidence regarding the association between play and academic achievement in the primary school setting.

One of the challenges to comparing this work to other studies is the various ways in which "play-based learning" is defined in the literature and operationalised in practice. Recently Zosh et al. (2018) proposed a multidimensional definition of play that creates a spectrum ranging from free play (no guidance or support) to guided play and games (including purposeful adult support while maintaining playful elements) (Zosh et al., 2018). The pedagogies implemented in the present study range along the spectrum of play conceptualised by Zosh et al. (2018) from guided play to "playful instruction" as the activities are initiated by the teacher with an explicit learning goal in mind, and depending on the activity, they are directed by the teacher and/or by the child (Zosh et al., 2018). A similar approach was utilised in the "Big Math for Little Kids" play-based programme implemented for 4-5-year-old children from low-income communities in New York over 2 years (Lewis Presser et al., 2015). The programme demonstrated a positive impact of mathematic knowledge. A recent scoping review of the literature on play-based pedagogies in kindergarten education noted evidence for a positive impact on various elements of mathematical learning, including measurement, logico-mathematical thinking, number sense and spatial skills (Pyle et al., 2017). Of note is that the above-mentioned research involved children in early childhood (prekindergarten and kindergarten). A related teaching method-physically active learning-has been used more widely with children of primary school age and proven successful in enhancing both learning and health outcomes (Martin \& Murtagh, 2017a). Several programmes have focussed specifically on mathematical learning and point to the potential for play -based learned to be extended beyond early years setting.

The effect of group on test scores was different for male and female students in term 2, but not term 1 . Girls in this study achieved similar scores to the boys in term 1 and higher scores in term 2. This may suggest that girls particularly benefited from learning the term 2 mathematical concepts using play-based approaches. While there is some evidence that girls and boys perform differently in specific content domains in international Maths assessments, with girls outperforming boys in data, boys excelling in number and both performing similarly in shape and measure (Mullis et al., 2012), it is unclear if the results of the current study are 
affected by this as a combination of content domains were taught across both terms. Despite male bias in school mathematic textbooks in Palestine (Karama, 2020), eighth grade female students in Palestine score slightly higher in international assessments of maths than their male counterparts (Mullis et al., 2008, 2012). Given the underachievement of male students in Palestine compared to the international average of males in these studies, further investigation of the underlying causes of this gender disparity in response to play-based learning is warranted. Exposure to play-based learning in the current study demonstrated a similarly positive effect on test scores for both girls and boys in term 1. Analysis of large international datasets demonstrates that, on average, males and females differ very little in mathematics achievement, despite more positive math attitudes and affect among males (Else-Quest et al., 2010). Previous studies which have evaluated gender differences in play, have consistently reported that boys express more negative affect, particularly aggression during play than girls (Fehr \& Russ, 2013; Russ, 2003). In their longitudinal study, evaluating the relationship between the processes involved in play and mathematics achievement, Wallace and Russ (2015) found that children whose play contained more imagination and more positive affect in particular, achieved better outcomes in mathematics assessments. Although our study did not evaluate the children's engagement in playful instruction, in line with previous research, it is possible that the girls in our study may have engaged in more positive affective elements during their play than the boys which could explain why girls performed better in the term 2 mathematics assessment. However, further research is needed to evaluate children's engagement in playful instruction to identify differences, if any, between the genders and the effect these may have on their achievements in mathematics.

A unique aspect of the present study is the challenging context in which the programme was implemented. Palestine is a highly marginalised area with high levels of poverty. Ongoing conflict and political unrest in the region has had a detrimental impact on education. This has led to low standards in children's critical thinking and life skill development (Ministry of Education \& Higher Education, 2017). The Palestinian Ministry of Education recognises the importance of these issues through a strategic goal to develop a student-centred teaching and learning pedagogy and environment (Ministry of Education \& Higher Education, 2017). Apart from the positive impact of play-based learning on academic achievement that the present study alludes to, previous research has demonstrated the positive impact of gamebased pedagogies on student enjoyment and teacher satisfaction (Martin \& Murtagh, 2017b). Teacher satisfaction and student enjoyment have been found to influence teacher decisions to implement such child-centred pedagogies (Benes et al., 2016; Lubans et al., 2008). Additionally, student enjoyment has been found to maintain student interest and engagement (Dishman et al., 2005). Since attendance at school is a priority (UNESCO, 1991) such outcomes are likely to be of even more importance in terms of child welfare and development in conflict/marginalised settings and are worthy of further investigation in relation to the programme discussed here.

We have identified several further research recommendations in relation to this work. A randomised controlled trial—or a pragmatic evaluation of existing programmes-should be conducted to examine the effectiveness of the play-based programme on mathematical learning and academic achievement. Evidence points to additional benefits of play beyond academic learning, including social-emotional development and general cognitive development (Pyle et al., 2017). The potential for Right To Play's play-based learning programme to influence social development should be investigated in further research. Such study would be complemented by qualitative research to explore teachers' and students' perspectives of the play-based approach in Palestinian schools. 
Similar to the current study, much of the research to date on academic benefits of play have focussed on the importance of teacher-directed and mutually directed play with an active teacher role (Danniels \& Pyle, 2018). The spectrum-based view of play allows us to question if different types of play might prove optimal for different learning outcomes (Zosh et al., 2018). In their study, evaluating the relationship between symbolic representation in pretend play and mathematics achievement, Hanline et al. (2008) found that practice with symbolic substitution in pretend play transfers to symbolic representation skills later required for mathematics and literacy. Wallace and Russ (2015) also reported that divergent thinking fluency developed through pretend play also later translated to mathematics achievement. Since these longitudinal studies demonstrate that processes inherent in free play such as symbolism, divergent thinking, affect, etc. can be transferred to academic skills, future research should explore whether the use of free play in academic lessons such as mathematics can evoke improvements in academic success similar to the current study.

Several possible pathways have been suggested for the link between play and academic achievement. This association is likely to be influenced by enhanced concentration and on-task behaviour, improved classroom room behaviour and enriched student-teacher relationships. School contentment is strongly related to academic achievement (Sigfsdttir \& Allegrante, 2009). Future research should explore the potential pathways and mediating factors that can explain-and perhaps maximise-how play-based approaches can influence learning, test scores and academic achievement.

\subsection{Limitations}

This study has limitations that may have impacted the findings and the overall generalisability of the results. First, a purposive sample was selected for the study, and it is therefore unclear if the sample is representative of the provincial or national school population. Second, the nature of the design means that causality cannot be determined. We do not have data on baseline academic performance of the intervention and control groups. Third, controlling for clustering at class and school level was not possible due to the nature of the data available. Fourth, the educational supervisors were not masked to group assignment when administering the tests. Lastly, while the mathematics assessment was designed by a group of experienced education supervisors, the validity and reliability of the instrument has not been established so the results may need to be interpreted with caution. Future similar studies should assess the validity and reliability of the mathematics assessment tool.

\section{Conclusion}

This non-randomised parallel group study revealed differences in examination scores for maths between intervention and control groups, with the intervention group attaining higher scores across the school year. This data suggests a link between play-based learning approaches and academic achievement; a controlled trial or pragmatic evaluation is warranted to confirm effectiveness of the programme. Such novel pedagogical approaches have the potential to influence educational policy developments within Palestine and other Arabicspeaking countries in the Middle East region.

Acknowledgements The authors thank Kholoud Salama and Samir Jouba for supplying background information in relation to the project. 
Author contributions CRediT author statement EM: Conceptualisation, Methodology, Analysis, Writing-original draft, Writing-review \& editing, Supervision. JS: Conceptualisation, Resources, Writing-review \& editing. RM: Methodology, Analysis, Writing-original draft, Writing-review \& editing, Supervision.

Funding Open Access funding provided by the IReL Consortium. N.

Data availability Available from the authors upon request.

Code availability Not applicable.

\section{Declarations}

Conflicts of interest Elaine Murtagh and Rosemarie Martin declare no conflicts of interest. Jamil Sawalma is employed by Right To Play.

Open Access This article is licensed under a Creative Commons Attribution 4.0 International License, which permits use, sharing, adaptation, distribution and reproduction in any medium or format, as long as you give appropriate credit to the original author(s) and the source, provide a link to the Creative Commons licence, and indicate if changes were made. The images or other third party material in this article are included in the article's Creative Commons licence, unless indicated otherwise in a credit line to the material. If material is not included in the article's Creative Commons licence and your intended use is not permitted by statutory regulation or exceeds the permitted use, you will need to obtain permission directly from the copyright holder. To view a copy of this licence, visit http://creativecommons.org/licenses/by/4.0/.

\section{Appendix 1}

Curriculum outcomes assessed in the examinations

\begin{tabular}{|c|c|c|}
\hline Grade & Semester 1 & Semester 2 \\
\hline \multirow[t]{2}{*}{1} & $\begin{array}{l}\text { - Proficiency in reading numbers and writing } \\
\text { and representation and compare them } \\
\text { within the number } 20\end{array}$ & $\begin{array}{l}\text { - Mastering the addition and subtraction } \\
\text { within the number } 99\end{array}$ \\
\hline & $\begin{array}{l}\text { - Proficiency in the addition and subtraction } \\
\text { within the number } 9\end{array}$ & $\begin{array}{l}\text { Distinguish between square, rectangle, } \\
\text { triangle, cube, parallelogram, rectangle and } \\
\text { ball }\end{array}$ \\
\hline \multirow[t]{2}{*}{2} & $\begin{array}{l}\text { - Classifies the numbers to odd and even } \\
\text { numbers within } 99,999\end{array}$ & $\begin{array}{l}\text { - Creates sentences multiplying numbers (23 } \\
4510 \text { ) and uses multiplication facts to solve } \\
\text { life problems }\end{array}$ \\
\hline & $\begin{array}{l}\text { - Read data represented by pictures and } \\
\text { represent other data in pictures as well }\end{array}$ & $\begin{array}{l}\text { Represents the following fractions: half, } \\
\text { quarter, third, five }\end{array}$ \\
\hline \multirow[t]{2}{*}{3} & $\begin{array}{l}\text { - Represent the numbers and determine the } \\
\text { decimal value of the numbers in } 9999 \text { in } \\
\text { different ways }\end{array}$ & $\begin{array}{l}\text { - Give the division facts corresponding to } \\
\text { multiplication facts of the numbers }(23456 \\
789 \text { ) }\end{array}$ \\
\hline & $\begin{array}{l}\text { Distinguish between types of angles and } \\
\text { draw it }\end{array}$ & $\begin{array}{l}\text { - Distinguish between the concepts of space } \\
\text { and perimeter in a simple way }\end{array}$ \\
\hline \multirow[t]{2}{*}{4} & $\begin{array}{l}\text { - Represent numbers and determine the } \\
\text { decimal value of numbers within millions in } \\
\text { different ways }\end{array}$ & $\begin{array}{l}\text { - Proficient in reading decimal and decimal } \\
\text { numbers and writing and comparing them }\end{array}$ \\
\hline & $\begin{array}{l}\text { - Distinguish between fractional and } \\
\text { fractional number and non-real fractions }\end{array}$ & $\begin{array}{l}\text { - The conversion between units of } \\
\text { measurement is used to solve life issues }\end{array}$ \\
\hline
\end{tabular}




\section{Appendix 2}

Sample maths assessment (translated from Arabic)

- Select a quarter (1/4) of the group

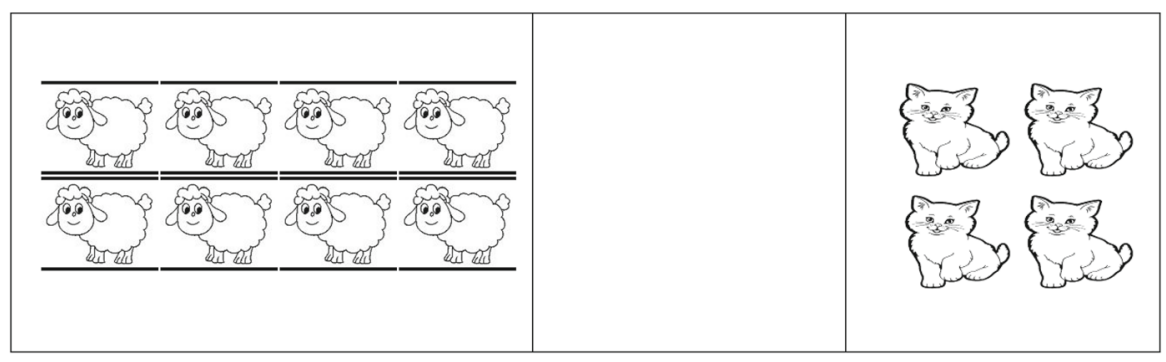

- Connect between the fraction and what it represents
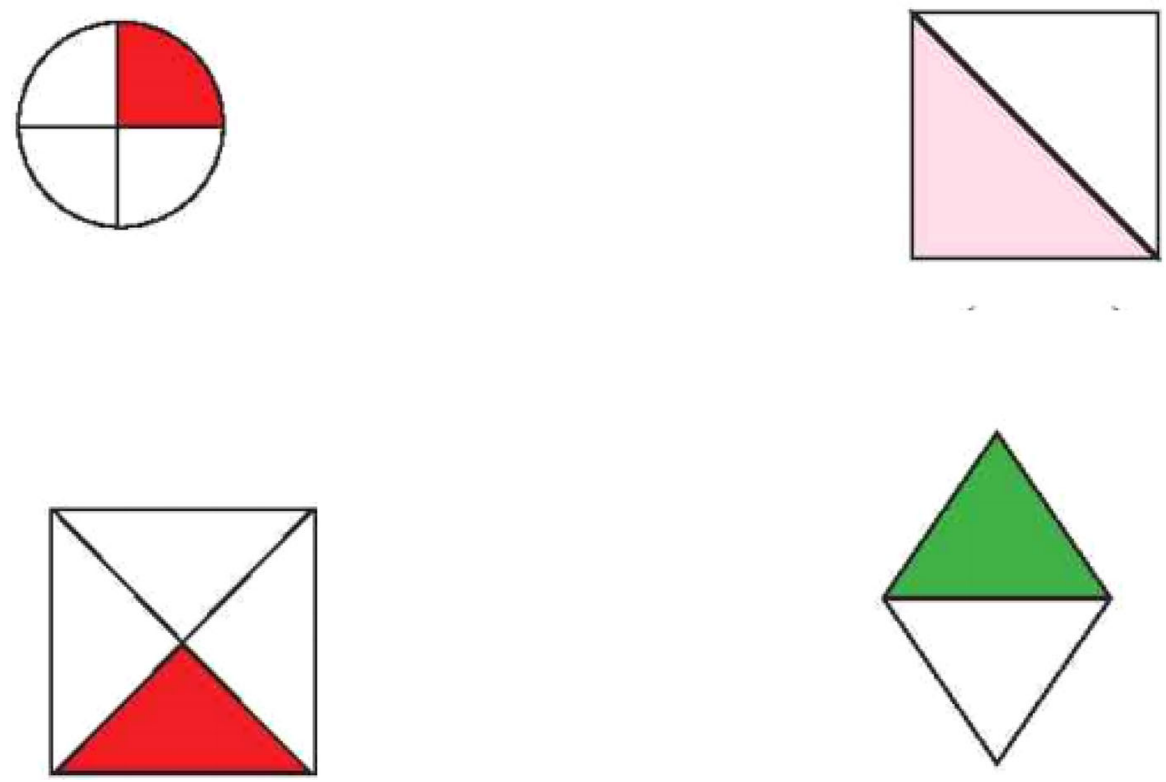

- Write the fraction represented by the shaded part 


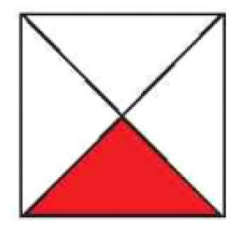

( )

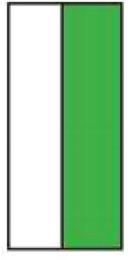

( )

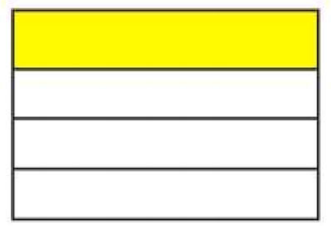

( )

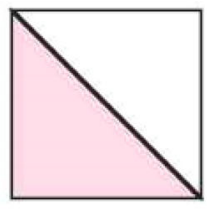

( )

- Draw shapes representing the following multiplication
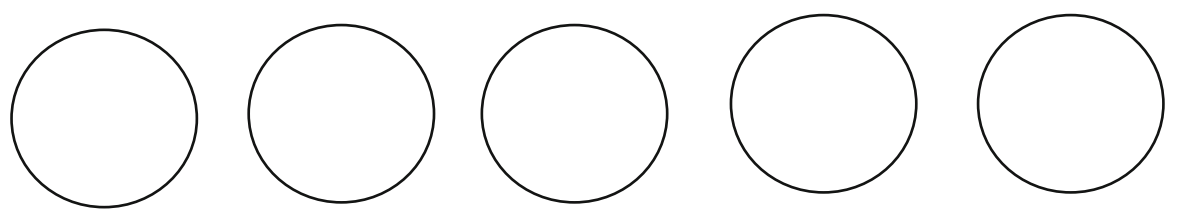

$5 \times 3=$
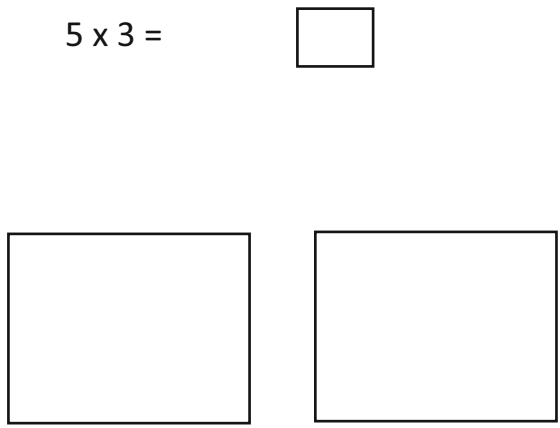

$2 \times 3=$

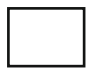

- Express the following with multiplication sentence 

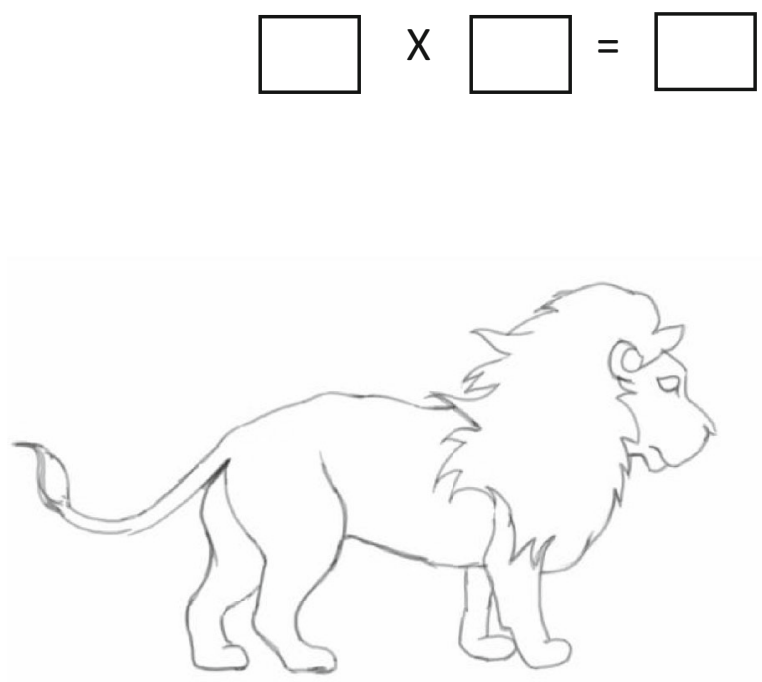

\section{Appendix 3}

Example 1: Measurement: Weight Stage: Early
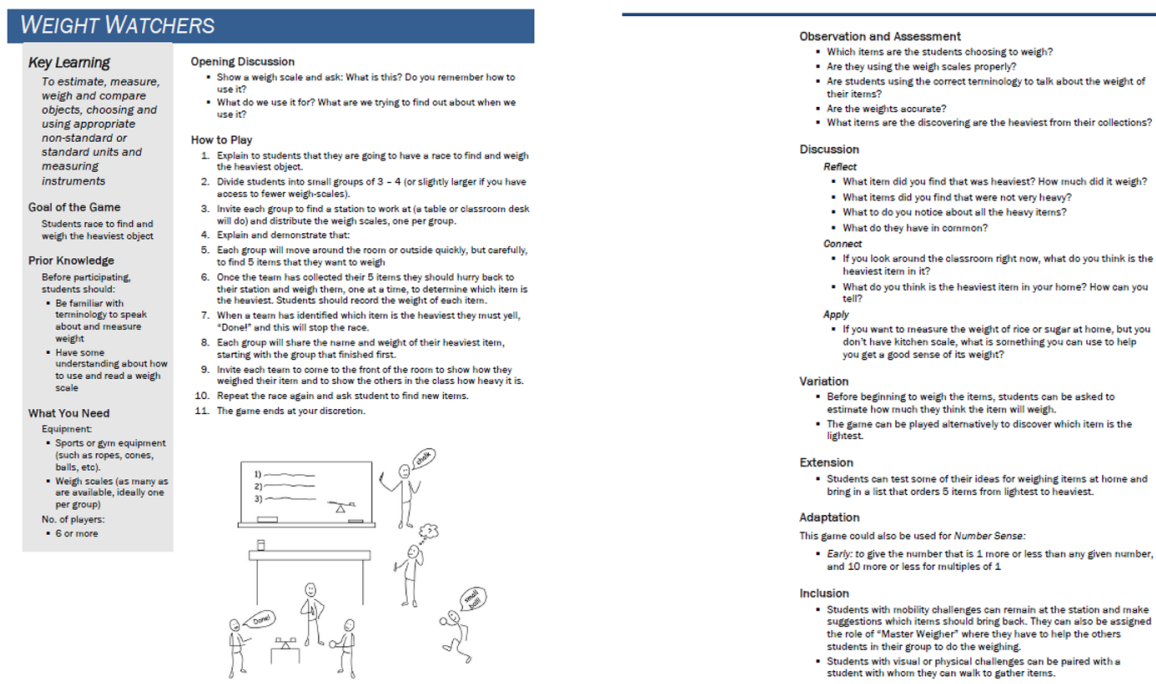
Example 2: Strand: Data Management Stage: Emerging

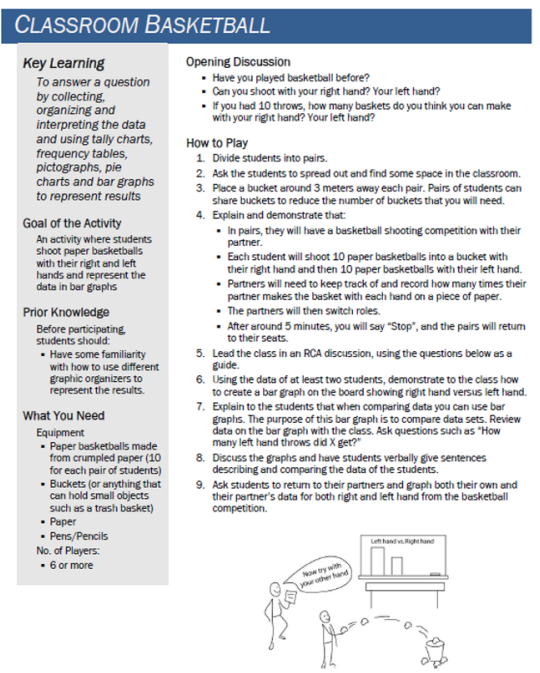

Example 3: Strand: Spatial Sense Stage: Expanding

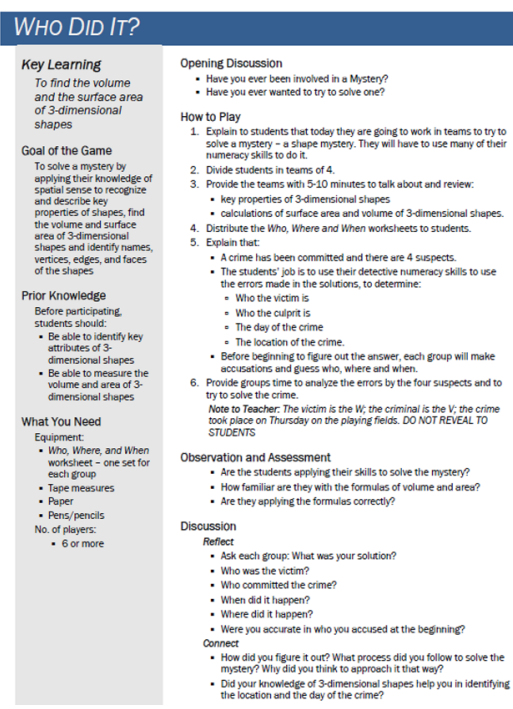

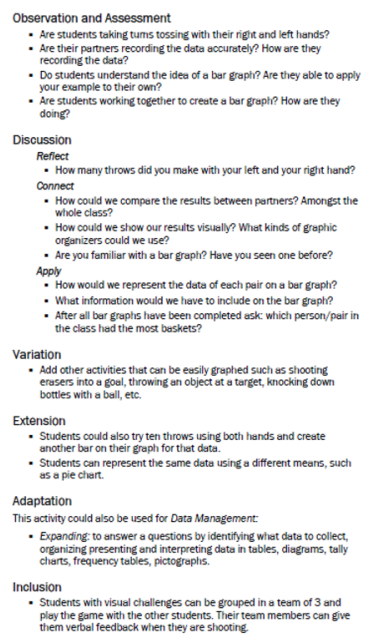

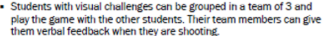

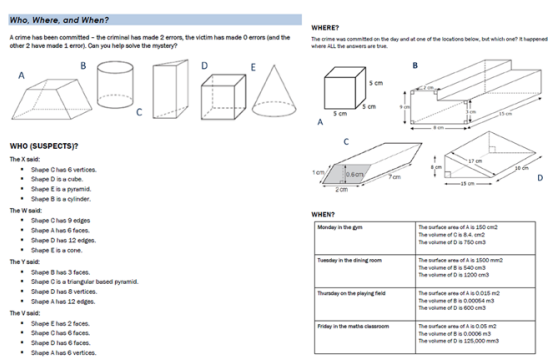

\section{References}

Alfieri, L., Brooks, P. J., Aldrich, N. J., \& Tenenbaum, H. R. (2011). Does discovery-based instruction enhance learning? Journal of Educational Psychology, 103(1), 1.

Al-Ramahi, N., \& Davies, B. (2002). Changing primary education in Palestine: Pulling in several directions at once. International Studies in Sociology of Education, 12(1), 59-76. https://doi.org/10.1080/ 09620210200200083 
Baker, F. S. (2014a). Teachers' views on play-based practice in Abu Dhabi kindergartens. International Journal of Early Years Education, 22(3), 271-286.

Baker, F. S. (2014b). Tensions in policy and practice: Influences on play in Abu Dhabi's new school model KG framework. Early Child Development and Care, 184(12), 1830-1842.

Balfanz, R., Ginsburg, H. P., \& Greenes, C. (2003). The big math for little kids early childhood mathematics program. (Early Childhood Corner). Teaching Children Mathematics, 9(5), 264-269.

Benes, S., Finn, K. E., Sullivan, E. C., \& Yan, Z. (2016). Teachers' perceptions of using movement in the classroom. Physical Educator, 73(1), 110.

Bennett, J., \& Tayler, C. P. (2006). Starting strong II: Early childhood education and care. Paris, France: OECD.

Bennett, D. A. (2001). How can I deal with missing data in my study? Australian and New Zealand Journal of Public Health, 25(5), 464-469.

Biggs, J. B. (2011). Teaching for quality learning at university: What the student does: McGraw-hill education (UK).

Blanca, M. J., Alarcón, R., Arnau, J., Bono, R., \& Bendayan, R. (2017). Non-normal data: Is ANOVA still a valid option? Psicothema, 29(4), 552-557.

Brooker, L., \& Edwards, S. (2010). Engaging play. Open University Press.

Bustamante, A. S., Schlesinger, M., Begolli, K. N., Golinkoff, R. M., Shahidi, N., Zonji, S., et al. (2020). More than just a game: Transforming social interaction and STEM play with Parkopolis. Developmental Psychology, 56(6), 1041-1056.

Cornelli Sanderson, R. (2010). Towards a new measure of playfulness: The capacity to fully and freely engage in play: Loyola University Chicago.

Danniels, E., \& Pyle, A. (2018). Defining play-based learning. In B. M. Tremblay, R. E, Peters, R. DeV (Ed.), Encyclopedia on early childhood development.

Darling, J. (1994). Child-centred education and its critics (Vol. Book, Whole), Paul Chapman.

Darling-Hammond, L. (1994). Performance-based assessment and educational equity. Harvard Educational Review, 64(1), 5-31. https://doi.org/10.17763/haer.64.1.j57n353226536276

de la Sablonnière, R., Taylor, D. M., \& Sadykova, N. (2009). Challenges of applying a student-centered approach to learning in the context of education in Kyrgyzstan. International Journal of Educational Development, 29(6), 628-634.

Dewey, J. (1906). The child and the curriculum. University of Chicago press.

Diamond, A. (2014). Want to optimize executive functions and academic outcomes? Simple, just nourish the human spirit. In Minnesota symposium in child psychology, 37, Oct, 2011, university of minnesota, MN, US; based on presentations at the aforementioned symposium, John Wiley \& Sons Inc

Dishman, R. K., Motl, R. W., Saunders, R., Felton, G., Ward, D. S., Dowda, M., et al. (2005). Enjoyment mediates effects of a school-based physical-activity intervention. Medicine and Science in Sports and Exercise, 37(3), 478-487.

Else-Quest, N. M., Hyde, J. S., \& Linn, M. C. (2010). Cross-national patterns of gender differences in mathematics: A meta-analysis. Psychological Bulletin, 136(1), 103-127.

Fehr, K. K., \& Russ, S. W. (2013). Aggression in pretend play and aggressive behavior in the classroom. Early Education \& Development, 24(3), 332-345.

Fung, C. K. H., \& Cheng, D. P. W. (2012). Consensus or dissensus? Stakeholders' views on the role of play in learning. Early Years, 32(1), 17-33. https://doi.org/10.1080/09575146.2011.599794

Ghafouri, F., \& Wien, C. A. (2005). "Give us a privacy": Play and social literacy in young children. Journal of Research in Childhood Education, 19(4), 279-291.

Government of Ireland (1999). Primary school curriculum. Dublin: The Stationary Office.

Gray, C., \& Ryan, A. (2016). Aistear vis-à-vis the primary Curriculum: The experiences of early years teachers in Ireland. International Journal of Early Years Education, 24(2), 188-205.

Habgood, M. J., \& Ainsworth, S. E. (2011). Motivating children to learn effectively: Exploring the value of intrinsic integration in educational games. The Journal of the Learning Sciences, 20(2), 169-206.

Hanline, M. F., Milton, S., \& Phelps, P. C. (2008). A longitudinal study exploring the relationship of representational levels of three aspects of preschool sociodramatic play and early academic skills. Journal of Research in Childhood Education, 23(1), 19-28.

Hegde, A. V., \& Cassidy, D. J. (2009). Kindergarten teachers' perspectives on developmentally appropriate practices (DAP): A study conducted in Mumbai (India). Journal of Research in Childhood Education, 23(3), 367-381.

Hirsh-Pasek, K., Golinkoff, R. M., Berk, L. E., \& Singer, D. (2009). A mandate for playful learning in preschool: Applying the scientific evidence. Oxford University Press. 
Hirsh-Pasek, K., Zosh, J. M., Golinkoff, R. M., Gray, J. H., Robb, M. B., \& Kaufman, J. (2015). Putting education in "educational" apps: Lessons from the science of learning. Psychological Science in the Public Interest, 16(1), 3-34.

Hunter, T., \& Walsh, G. (2014). From policy to practice?: The reality of play in primary school classes in Northern Ireland. International Journal of Early Years Education, 22(1), 19-36. https://doi.org/10.1080/ 09669760.2013 .830561

Hyvonen, P. T. (2011). Play in the school context? The perspectives of finnish teachers. Australian Journal of Teacher Education, 36(8), 5.

Johnson, D., Johnson, R., \& Smith, K. (1998). Active learning: Cooperation in the college classroom (Johnson \& Johnson (2004) Op. cit). Edina, MN: Interaction Book Company.

Karama, M. J. (2020). Gender bias in school mathematics textbooks from grade 1 to 12 in Palestine. Journal of International Women's Studies, 21(1), 162-171.

Khales, B., \& Meier, D. (2013). Toward a new way of learning-promoting inquiry and reflection in Palestinian early childhood teacher education. The New Educator, 9(4), 287-303. https://doi.org/10.1080/1547688X. 2013.841504

Kim, M. (2004). Teachers' philosophical orientation and practices: A study of novice preschool teachers in South Korea. Contemporary Issues in Early Childhood, 5(3), 276-292.

Kotsopoulos, D., Makosz, S., Zambrzycka, J., \& McCarthy, K. (2015). The effects of different pedagogical approaches on the learning of length measurement in kindergarten. Early Childhood Education Journal, 43(6), 531-539.

Krasnor, L. R., \& Pepler, D. J. (1980). The study of children's play: Some suggested future directions. New Directions for Child and Adolescent Development, 1980(9), 85-95.

Lazonder, A. W., \& Harmsen, R. (2016). Meta-analysis of inquiry-based learning: Effects of guidance. Review of Educational Research, 86(3), 681-718.

le Cessie, S., Goeman, J. J., \& Dekkers, O. M. (2020). Who is afraid of non-normal data? Choosing between parametric and non-parametric tests. European Journal of Endocrinology, 182(2), E1-E3.

Lewis Presser, A., Clements, M., Ginsburg, H., \& Ertle, B. (2015). Big math for little kids: The effectiveness of a preschool and kindergarten mathematics curriculum. Early Education and Development, 26(3), 399-426.

Ling-Yin, L. A. (2006). Steering debate and initiating dialogue: A review of the Singapore preschool curriculum. Contemporary Issues in Early Childhood, 7(3), 203-212.

Lubans, D. R., Foster, C., \& Biddle, S. J. (2008). A review of mediators of behavior in interventions to promote physical activity among children and adolescents. Preventive Medicine, 47(5), 463-470.

Lynch, M. (2015). Guys and dolls: A qualitative study of teachers' views of gendered play in kindergarten. Early Child Development and Care, 185(5), 679-693.

Martin, R., \& Murtagh, E. (2017a). Effect of active lessons on physical activity, academic, and health outcomes: A systematic review. Research Quarterly for Exercise and Sport, 88, 149-168.

Martin, R., \& Murtagh, E. M. (2017b). Teachers' and students' perspectives of participating in the 'active classrooms' movement integration programme. Teaching and Teacher Education, 63, 218-230.

McGuinness, C., Sproule, L., Bojke, C., Trew, K., \& Walsh, G. (2014). Impact of a play-based curriculum in the first two years of primary school: Literacy and numeracy outcomes over seven years. British Educational Research Journal, 40(5), 772-795. https://doi.org/10.1002/berj.3117

McInnes, K., Howard, J., Miles, G., \& Crowley, K. (2011). Differences in practitioners' understanding of play and how this influences pedagogy and children's perceptions of play. Early Years, 31(2), 121-133.

Ministry of Education and Higher Education. (2017). Education sector strategic plan 2017-2022. Ramallah, Palestine: Palestinian Authority.

Moyles, J. (2014). The excellence of play. New York: McGraw-Hill Education.

Mullis, I. V., Martin, M. O., Gonzalez, E. J., \& Chrostowski, S. J. (2008). TIMSS 2007 international mathematics report: Findings from IEA's trends in international mathematics and science study at the fourth and eighth grades. Chestnut Hill, MA: TIMSS \& PIRLS International Study Center, Boston College.

Mullis, I. V., Martin, M. O., Foy, P., \& Arora, A. (2012). TIMSS 2011 international results in mathematics. Chestnut Hill, MA: TIMSS \& PIRLS International Study Center

Pan, Y.-J., \& Li, X. (2012). Chapter 1 kindergarten curriculum reform in mainland China and reflections. In Sutterby, J.A. (Ed.) Early education in a global context (Advances in Early Education and Day Care, Vol. 16) (pp. 1-26). Bingley: Emerald Group Publishing Limited. https://doi.org/10.1108/S02704021(2012)0000016004.

Piaget, J. (1962). Play, dreams and imitation in childhood. Norton.

Pramling Samuelsson, I., \& Carlsson, M. A. (2008). The playing learning child: Towards a pedagogy of early childhood. Scandinavian Journal of Educational Research, 52(6), 623-641. https://doi.org/10. 1080/00313830802497265 
Pramling Samuelsson, I., \& Johansson, E. (2006). Play and learning-inseparable dimensions in preschool practice. Early Child Development and Care, 176(1), 47-65.

Pui-Wah, D. C., \& Stimpson, P. (2004). Articulating contrasts in kindergarten teachers' implicit knowledge on play-based learning. International Journal of Educational Research, 41(4-5), 339-352.

Pyle, A., DeLuca, C., \& Danniels, E. (2017). A scoping review of research on play-based pedagogies in kindergarten education. Review of Education, 5(3), 311-351.

Right To Play (2017) Minimum standards for Palestinian Active Classrooms. Palestine: Right To Play \& Ministry of Education and Higher Education.

Right To Play. (2020). Our Work. Retrieved on 31 March 2020 from https://righttoplay.com/en/our-work/.

Russ, S. W. (2003). Play in child development and psychotherapy: Toward empirically supported practice. Routledge.

Sarama, J., \& Clements, D. H. (2006). Mathematics in kindergarten. YC. Young Children, 61(5), 38.

Shinn, C. (2012). Teacher education reform in palestine: policy challenges amid donor expectations 1 . Comparative Education Review, 56(4), 608-633. https://doi.org/10.1086/667434

Sigfsdttir, I. D., \& Allegrante, J. P. (2009). Adolescent health behavior, contentment in school, and academic achievement. American Journal of Health Behavior, 33(1), 69-79.

Sumsion, J., Barnes, S., Cheeseman, S., Harrison, L., Kennedy, A., \& Stonehouse, A. (2009). Insider perspectives on developing belonging, being \& becoming: The early years learning framework for Australia. Australasian Journal of Early Childhood, 34(4), 4-13.

Synodi, E. (2010). Play in the kindergarten: The case of Norway, Sweden, New Zealand and Japan. International Journal of Early Years Education, 18(3), 185-200.

Tafa, E. (2008). Kindergarten reading and writing curricula in the European Union. Literacy, 42(3), 162-170.

Turshan, M. (2019). Impact study report: The impact of play based learning methodology on acquiring numeracy skills/Mathematics subject for basic stages for Public School's Students for Grades 1, 2, 3 and 4. Ramallah, Palestine: Right To Play.

UNESCO. (1991). Palestine: Priority projects for educational development. UNESCO Publications.

Vong, K.-I. (2012). Play-a multi-modal manifestation in kindergarten education in China. Early Years, 32(1), $35-48$.

Wallace, C. E., \& Russ, S. W. (2015). Pretend play, divergent thinking, and math achievement in girls: A longitudinal study. Psychology of Aesthetics Creativity and the Arts, 9(3), 296.

Wallerstedt, C., \& Pramling, N. (2012). Learning to play in a goal-directed practice. Early Years, 32(1), 5-15.

Wood, E. A. (2014). Free choice and free play in early childhood education: Troubling the discourse. International Journal of Early Years Education, 22(1), 4-18.

Zosh, J. M., Hirsh-Pasek, K., Hopkins, E. J., Jensen, H., Liu, C., Neale, D., et al. (2018). Accessing the inaccessible: Redefining play as a spectrum. Frontiers in Psychology, 9, 1124.

Publisher's Note Springer Nature remains neutral with regard to jurisdictional claims in published maps and institutional affiliations. 